\title{
NIÑO, JUEGO Y DIMENSIÓN LÚDICA: PRIMEROS NIVELES BIO- EPISTÉMICOS DE LIMITACIÓN
}

Child, play and ludic dimension: First levels bio-epistemic limitation

Criança, jogo e dimensão lúdica: Primeiros níveis bio-epistêmica de limitação

\section{Oscar Felipe Díaz Antillanca (1) (2)}

(1) Universidad Austral de Chile. Fono: +569 73810501 Correo Electrónico: osfedian@gmail.com

(2) El siguiente artículo se desprende de la investigación "Complejidad y simpleza en el juego en el contexto escolar", perteneciente al Proyecto Fondecyt $\mathrm{N}^{\circ}$ 1120761 "Conocimiento y comunidad escolar: procesos de interpretación de las dinámicas relacionales escolares en la educación como configuración cognitiva situada" del Dr. Sergio Toro Arévalo (Uach).

\section{Resumen}

La finalidad de este artículo es tensionar la crisis lúdica que experimentan los niños y niñas al ingresar al terreno escolarizado, cuyo paradigma estático se evidencia en niveles bio-epistémicos de limitación, en relación con el vínculo fraterno de educación y juego. A su vez, es la infancia la etapa más relevante para el desarrollo integral del ser humano, cuyas posibilidades formativas son abundantemente ligadas a la potenciación de la dimensión lúdica. Esta reflexión propositiva, emerge desde la observación y trabajo de campo etnográfico de la investigación titulada "Complejidad y simpleza del juego en el contexto escolar: Análisis de las manifestaciones de juego y dimensión lúdica del educador de aula", donde se visualizaron clases de kinder, nivel básico y nivel medio. Exponiendo la problemática relación del juego con la enseñanza escolarizada, se esgrime la crítica al primer contacto del nuevo educando con la escuela y cómo este encuentro resulta limitante, desde el punto de vista biológico, cognitivo y social.

Palabras clave: juego; educación; lúdica; aprendizaje.

\section{Abstract}

The purpose of this article is to stress the playful crisis experienced by children schooled to enter the field, the static paradigm is evident in bio-epistemic limitation levels in relation to the fraternal bond education and play. In turn, childhood is the most relevant for the integral human development stage, whose educational possibilities are 
thoroughly linked to enhancing the playful dimension. This purposeful reflection, emerges from observation and ethnographic fieldwork research entitled "Complexity and simplicity of the game in the school context: analysis of the manifestations of play and playful dimension of the classroom teacher," where kindergarten classes were visualized, basic and medium level. Exposing the problematic relationship with the schooling game teaching, criticism of the new student's first contact with the school and how this event is limited, in terms of biological, cognitive and social view is put forward.

Keywords: play; education; ludic; learning.

\section{Resumo}

O objetivo deste artigo é enfatizar a crise brincalhão vivida por crianças escolarizadas a entrar no campo, o paradigma estático é evidente em níveis de limitação de bioepistêmica em relação à educação laço fraterno e jogo. Por sua vez, a infância é o mais relevante para a fase de desenvolvimento humano integral, cuyas posibilidades educacionais são completamente ligado ao reforço da dimensão lúdica. Esta reflexão intencional, emerge da observação e pesquisa etnográfica intitulada trabalho de campo "Complexidade e simplicidade do jogo no contexto escolar: análise das manifestações do jogo e dimensão lúdica do professor em sala de aula", onde as aulas do jardim de infância foram visualizados, nível básico e médio. Expor a relação problemática com o ensino jogo escolaridade, a crítica do primeiro contacto, o novo aluno com a escola e como este evento é limitado, em termos de vista biológico, cognitivo e social é apresentada.

Palavras Chave: jogo; educação; lúdica; aprendizagem.

\section{Introducción}

Todas nuestras interacciones en el seno de la infancia, tengan o no ciertos niveles de complejidad, apuntan al aprendizaje inevitable como acceso a conocer el entorno inmediato. Este conocer dialoga con aspectos educativos y lúdicos impregnados de una elevada curiosidad. Curiosidad que da paso a procesos absortivos únicos, significativos, motivantes, de mimesis y cuya huella de memoria es absolutamente poderosa. 
El infante se relaciona con el mundo, a través de pequeños primeros contactos. Comprendiendo las formas, los colores, aromas, el lenguaje y símbolos que debe aprehender como posibilidad obligada de vida. Todos estos procesos caóticos, no obstante, auténticos, poseen una supra creatividad y multiplicidad de maneras de llegar a observar situaciones, momentos y enseñanzas. El aprendizaje se da favorablemente por el uso del juego o de juegos, privilegiando un acceso libre, espontáneo y no planificado. Sin embargo, mencionados primeros pasos son potenciados hasta la entrada a la escuela. Es decir, de pasar del aprender el mundo de cualquier forma a otra escolarizada y castrante.

Por su lado, el juego ha sido considerado un aspecto fundamental en el aprendizaje del ser humano, sobre todo en el desarrollo infantil, desde tiempos antiquísimos. El juego, como tema, ha sido investigado desde diferentes perspectivas, entendido desde distintas visiones y utilizado en transversales disciplinas. Existen múltiples estudios y autores que dan cuenta de la relevancia del juego como estrategia de aprendizaje, y por supuesto como elemento central de nuestra condición humana.

Todos alguna vez hemos jugado, siendo seducidos por las dinámicas lúdicas para conocer nuestro entorno. Pero, pareciera que a medida que vamos creciendo, la sociedad ya no nos permite jugar, y la institución escolar al escolarizarnos, va cediendo terreno a la mecánica, a la rutina y a la obsesión (ya sea consciente o inconsciente) de aniquilar la dimensión lúdica del niño.

Entonces ¿Cómo se relaciona el juego del niño con el contexto escolar en sus primeros contactos? Considerando que el juego es inevitable para el ser humano y que todos jugamos en diferentes niveles. Este artículo dará cuenta de esta relación, centrándose en el educando pre-escolar y de primer nivel básico de enseñanza (NB1), fundamentándose en el análisis etnográfico de la investigación "Complejidad y simpleza del juego en el contexto escolar: Análisis de las manifestaciones de juego y dimensión lúdica del educador de aula" (Región de los Lagos, Chile), cuya extensión de 2 años, permitió adentrarnos en las interacciones fluctuantes del terreno escolarizado

\section{Jugando, aprendiendo, jugando: Bucle educativo-lúdico del conocer}

Es en el período de la infancia, ya sea primera, temprana o cualquier adjetivo que se estime conveniente, dondes los niños experimentan los cambios más profundos, se 
preparan para complejizar habilidades, desarrollándose corporal y cerebralmente. También es el punto donde adquirimos (de manera espontánea) una forma predilectamente-favorita de acceder al conocer. El niño juega y aprende simultáneamente, sin ningún ánimo de dicotomizar ambas acciones. Partimos de la base que el jugar es innegable para el ser humano, y ha estado siempre en nuestra órbita cultural y como generador de culturas (Huizinga, 2000) y potenciador de prácticas sociales (Díaz Mejía, 2006). El juego es serio y complejo. Más aún, cuando el mundo se nos presenta como un abanico de posibilidades biológicas, físicas, termodinámicas, químicas, intelectuales, ecológicas, etc. El niño, en la experiencia inmediata va construyendo una simetría entre juego, aprendizaje, recreación y educación. A esta simbiosis le denominamos bucle educativo-lúdico del conocer. Es decir, cualquier intento de acceder al conocimiento, mediante interacciones lúdicas, dinámicas y/o sinérgicas. De aquí, la importancia del juego como fenómeno cultural de desarrollo y de instancia para propender aprendizaje (posibilidad didáctica).

Hablamos de juego cuando nos referimos a una actividad sumamente relevante en la existencia del ser, sobre todo porque otorga un desarrollo del cuerpo, de la inteligencia y de la afectividad (Unesco, 1980). El juego es la actividad humana que por excelencia requiere una inocencia total (Maturana, 2003), que se da de manera libre, espontánea, autónoma y sin objetivo propuesto por alcanzar (Butendieck, 2003). El Juego propende de manera sencilla un aprendizaje global, que puede ser motriz, afectivo, social y cognitivo (García, 1998), además de poseer una fuerza motivadora que atrae a los niños a través de la curiosidad natural (Puig, 1994), representando profundos cambios cognitivos y experienciales, que la escuela desconoce. Además, el juego puede integrar fácilmente los contenidos curriculares que la escuela pregona (Fleer, 1996). El juego, entonces, carece de finalidad alguna, aunque pudiéramos dársela. El juego encierra y expande una riqueza educativa superlativa, situada fuera de la vida corriente y que puede absorber al jugador sin obtener beneficio alguno (Huizinga, 2000) caracterizado por ser libre, incierto, improductivo y ficticio (Caillois, 1986).

«Juego y educación» siempre han estado unidos y mediatizados por el aprendizaje. Aprendemos a conocer el mundo a través del jugar [introyectiva, extensiva o proyectivamente] (Trigo, 1999). La mayoría de nuestros aprendizajes cuando niños, los adquirimos y disfrutamos de manera informal y a través de juegos. Por eso que la 
relación es tan estrecha y fraterna. El bucle educativo-lúdico del conocer es relevante, sobre todo en la infancia, aunque durante toda nuestra vida tenemos un derecho intransable de jugar y que en el gran tiempo que destinamos a la escuela, debiéramos seguir aprendiendo a través de éste, es decir, tener la oportunidad de seguir jugando.

\section{Primer día de clases: Escolarización, Orden y Certidumbre}

Nos atrevemos a decir, que la escuela es un espacio ajeno a la vida cotidiana. Todo transcurre de manera extraña, con relaciones y dinámicas distintas a las del espacio casa. El niño viene descubriendo el mundo sin límites. Si así lo desea, puede ver el mundo, tocarlo, olerlo, sentirlo, degustar si es necesario y reflexionarlo. Ha venido jugando-aprendiendo por algunos años de su vida, de forma libre y divertida. La vida es caótica, porque somos seres vivientes. Por supuesto las dinámicas del territorio educativo son diferentes a la prácticas educativo-sociales que se emplean en el territorio escolarizado (Calvo, 2007). Sin embargo, cuando el niño ingresa a la escuela y específicamente al aula, que en términos de Paymal (2010) podríamos denominar como "J-aulas", todo cambia. Y esto es un problema. Un problema grave, porque la transición no es para bien. Lo único cierto en la mente del niño (aún no escolarizado) es que debe ir porque es obligatorio. Tiene que asistir, porque así lo hicieron sus padres, hermanos, tíos, familia completa, etc. Y por supuesto, los demás niños también lo hacen. Lleva una mochila cargada de imaginación, creatividad, curiosidad y por supuesto, muchísimas ganas de jugar. Ha habitado el mundo, pero ahora deberá recorrer solamente el mapa escolar del mundo.

¿Qué podría salir mal en un lugar diseñado para aprender? La multiplicidad de respuestas podría dar para mucha discusión. No obstante, es un hecho que la forma de aprender escolarizada no permite todos los accesos al conocimiento. No abraza la idea de concebir que un contenido lingüístico, aritmético o artístico puede ser aprendido por distintos niños, de maneras distintas, con niveles distintos. Desde esta perspectiva, esto se convierte en una gran limitación. De partida, la orgánica de la institución escolar ya es nefasta. El niño no escolarizado observa que debe ir uniformado, debe cumplir horarios, entiende que será separado por su edad y curso, que deberá estar sentado por muchas horas, sólo obteniendo una libertad controlada de tiempo escaso denominada "recreo" y prestar mucha atención a un desfile de adultos llamados profesores. Ritual 
casi parecido a lo que realiza el papá cuando sale muy temprano de casa, regresando generalmente tarde (trabajo).

El primer obstáculo para la potenciación continua de la dimensión lúdica del niño en el terreno escolarizado es el paradigma estático imperante. Este paradigma responde a los códigos de una escuela neo-liberal que posee determinada forma de comprender la educación. Es estático, ya que ignora (conscientemente) otras formas de entender el conocer y por lo tanto se aleja de nuevas posibilidades formativas. Su finalidad es la dimensión productiva del educando, centrándose en la adquisición de ciertas competencias y habilidades homogeneizadoras, para acceder a cursos superiores, acreditarse y convertirse en hombres y mujeres de trabajo (Illich, 1977). En el trabajo de campo, se evidenciaron patrones comunes reflejos del paradigma estático y no dinámico. Existe una notorio obsesión de la escuela y transmitida por los docentes del orden. Evidentemente el juego es antinómico del orden porque es caótico e incontrolable. El orden preestablecido de la institución escolar e intento de control de la incertidumbre educativa, hace que la escuela privilegie metodologías de enseñanzaaprendizaje, de corte instructivo, rígido y evaluativo. Metodologías contrarias a la libertad con la que viene el niño jugando-aprendiendo-jugando. Aprendizaje, motivación, curiosidad, creatividad, emoción, diversión y satisfacción, como un todo se fundan en el hábitat silvestre de la pre-escolarización.

Los docentes observados y entrevistados, manifiestan que la primera función que deben cumplir es la de mantener el orden en la sala. Una vez ordenado el curso pueden presentar el contenido seleccionado. Sin embargo, este discurso es global. Ya que todos los actores presentes en la institución escolar pregonan lo mismo. Los niños corren, saltan, se molestan, gritan en el los recreos, pero siendo observados y penalizados por los inspectores de patio. Dentro del aula el movimiento es nulo. Sólo deben estar atentos a la pizarra y las instrucciones de la tarea "relevante" de turno.

Profundizando aún más, los mismos docentes indican que los inspectores les reclaman si sienten que el curso está bullicioso o muy activo. Desde esta lógica, el juego es sinónimo de desorden improductivo. Además, el sistema de planificaciones asegura en cierta medida la certidumbre de algunos resultados. El juego es $100 \%$ incertidumbre. Se juega por jugar y todo lo que ocurre ahí es aleatorio, pero cautivante (Caillois, 1996). 
El niño que camina por primera vez en el territorio escolarizado no está preocupado de la planificación o de cumplir objetivos académicos. Tiene la intención de seguir conociendo el mundo a su manera, porque viene con esa libertad. Al correr de los días, se da cuenta, que este choque no permite ser como quiere ser. Aprende a actuar de la forma en que es conveniente según el docente que le exija cierto comportamiento, y para su frustración el juego va quedando marginado a espacios bastante reducidos o a fugas lúdicas emergentes de sus compañeros o del entorno.

Entonces, los primeros niveles bio-epistémicos de limitación son el orden, como neutralizador del caos; la praxis docente, como arma de control y normalización; la planificación escolar, como bitácora y camino construido al vacío, sin considerar el movimiento de los educandos; la estandarización, como cima del proceso educativo neoliberal, competitivo y resultadista; el privilegio de un solo tipo de pedagogía, que tiene que ver más con el depósito de información que con el desarrollo humano; la disciplina, mal entendida como la represión de otras formas de acceso al conocimiento; y las relaciones jerárquicas, en contrariedad a relaciones dialógicas o heterárquicas. Por supuesto, a medida que el niño va pasando de cursos hasta llegar a nivel medio o universitario, los niveles bio-epistémicos de limitación se van complejizando, y se tornan mucho más filosóficos, existenciales. Entramando también, una aniquilación de la dimensión lúdica menos invisible y más efectiva.

\section{Después de estudiar, pueden jugar: Acceso educativo-lúdico-restringido, falsa} dicotomía y dimensión lúdica entrampada

Una vez que el niño conoce cómo debe desenvolverse en la escuela, las prácticas sociales y cognitivas se naturalizan. En las clases observadas, el docente siempre tiene el control de la situación y cualquier evento contrario a su planificación puede ser suprimido de manera inmediata. Este punto es importante, porque los docentes manifiestan cierta afición por el juego y se identifican como seres lúdicos. Es decir, se reconocen como un homo complexus y resaltan su homo faber, pero también su homo ludens (Morin, 2007). El tema problemático es que se levanta la categoría de Escuela Versus la categoría Casa. Los docentes, en la casa liberan su dimensión lúdica porque ahí son libres, en cambio en la escuela son distintos, suprimen su libertad de jugar porque Deben Ser otra cosa. Detrás del docente que enseña hay una persona que juega y 
detrás del educando hay un niño que juega también. Entonces, si ambos juegan ¿Qué pasa con el juego en el contexto escolar? Lo que ocurre es bastante simple: El jugar de los docentes y el jugar de los aprendientes, no son compatibles en el espacio internoexterno del aula. Por esta incompatibilidad, se produce una dicotomía artificial entre estudiar y jugar. Dentro del territorio escolar, el juego no es serio ni relevante, Por lo cual, está separado del estudio. No pueden coexistir en el aula. Por eso, en la mayoría de las clases observadas se repite el siguiente discurso docente: "Después de estudiar pueden jugar, es decir, después de hacer las cosas relevantes pueden quedar libres y realizar algo poco serio". Otras veces, el docente indica que deben finalizar la tarea en silencio porque ya se viene el primer recreo para que estén contentos. No se auspicia la curiosidad de los niños, y al final ellos se aburren de asistir a las mismas clases, con las mismas actividades. La dimensión lúdica del niño comienza a experimentar quiebres y estados de quietud que dañan la posibilidad de aprender de manera dinámica. No es extraño y cada vez es más recurrente que a los niños no les guste la educación que reciben, que no se motiven con los contenidos y con la forma en que se les explica, que no quieran asistir a clases, que se cansen, que deseen jugar en vez de multiplicar, sumar, leer un libro o conocer algún hecho histórico que no tiene relevancia para ellos. No es raro que deseen creativamente des-formarse a formarse en la institución escolar (Calvo, 2007). La pronta aniquilación de la dimensión lúdica, desde el discurso y acción de profesores hacia los educandos, nos habla de una evidente resistencia al juego.

\section{Tu juego no es mi juego: Manifestaciones lúdicas emergentes}

Se podría pensar que en kínder, jardín infantil o primero básico se respeta todavía la dimensión lúdica del niño, considerando que la didáctica es mucha más afectiva y dinámica. No obstante, aquí observamos una nueva situación. Ya mencionamos que el juego carece de algún beneficio productivo escolarizado, más que el placer y gozo en una espacio-tiempo determinado, aún cuando los beneficios biológicos, intelectuales y sociales están a la vista (Díaz Mejía, 2006). En una de las observaciones de campo fuimos testigos de la siguiente situación:

La educadora de parvulo, solicita a los niños sentarse en círculo. Todos con un cojín en mano quedan esperando las instrucciones. La sala estaba equipada con muchos juguetes en las esquinas. Uno de los niños se levanta del círculo y se dirige corriendo al 
lugar de los juguetes. La educadora, le llama la atención al niño y le exige que vuelva al círculo, para que realice la actividad preparada (interpretar una canción de forma coreográfica) . El niño se aburre y comienza a jugar con sus compañeros cercanos, que también se alejaron de la clase. Nuevamente la educadora le indica que se tranquilice para seguir con la dinámica propuesta. En este caso, nos dimos cuenta, que a pesar del espacio y las condiciones más dinámicas, la actividad ofrecida por la educadora, tampoco fue del gusto de los niños, porque es un juego propuesto y planificado por otra persona. Ellos abrazan la manifestación emergente del jugar y dejarse llevar por lo incierto. Dicha manifestación emergente lúdica, fue suprimida por la educadora. De forma más violenta se da en los niveles medios. En otra observación, un grupo de estudiantes de segundo medio juega a las cartas, en el fondo de la sala. El profesor se da cuenta de esto, interviene y se las quita. Dos estudiantes reclaman, pero el profesor insiste en que realicen su tarea o que al menos estén tranquilos, sentados si no van a realizar lo solicitado. Pasan unos minutos y los alumnos andan de pie, el profesor los anota y los envía a inspectoría. En ambas situaciones, las emergencias lúdicas son resistidas por los docentes, en vez de ser vistas como posibilidades didácticas. Sobre todo, en el caso de los más pequeños, la fuga lúdica reprimida, hace mella en la energía, interés y motivación por aprender. Se acostumbran a realizar lo solicitado, pero no es lo que realmente desean hacer en el momento. Cuando el juego viene propuesto desde el docente, tampoco existe una conexión con el educando, ya que se disfraza como didáctica novedosa, pero carente de sentido, libertad y contexto. Y por supuesto, el juego debe ser controlado porque es considerado como desorden y descontrol, por todos los agentes escolares. No se atiende a las diferentes dimensiones del niño y el aprendizaje holístico que debería tener (Paymal, 2010), a la potenciación del cerebrocuerpo-mente-espíritu, desarrollo humano integral, en general (Naranjo, 2007), sobre todo, desconociendo o no considerando la emocionalidad del niño. Las emociones que fundamentan sus razones de hacer (Maturana, 2003).

\section{Primera victoria del sistema escolar: Dimensión lúdica controlada y limitación aplicada}

Al término del primer día de clases, al pasar las semanas, al finalizar el primer año escolar, el niño no escolarizado (ahora escolarizado) se da cuenta que será dura la tarea de desarrollar su dimensión lúdica. Sabe que la batalla por el control. el orden y la 
certidumbre está perdida. Las redes del sistema escolar son petrificadas y repetidas hasta la médula, lo que hace que esa naturalización del paradigma educativo (estático) y su metodología de enseñanza (obsoleta), sea culturalmente aceptada por todos. Si el niño quiere jugar o pide juego en el contexto escolar, a los ojos de la comunidad educativa-escolarizada estará equivocado. En la escuela, existe un sistema tan normalizado, que si alguien intenta quebrarlo, pasa a estar a contracorriente y es juzgado. Existe un patrón que no permite otras posibilidades formativas. La dimensión lúdica es controlada desde la educación preescolar en adelante. El niño sabe y simula como otros le dicen que aprenda. Educadores simulan enseñar y los educandos simulan aprender, como un juego recursivo (Calvo, 2007). Aprendemos a hablar imitando y creando, a caminar, a bailar, a pensar de forma innata y lúdica (Huizinga,2000). Pero no lo hacemos tan fácil ni emocionante en las aulas escolares. Si los niños, niñas y jóvenes no reciben una educación que apunte a su desarrollo humano y potencialidades, éstos tendrán menos posibilidades de cumplir sus metas y sueños. De convertirse en seres de afecto, soñadores y con las herramientas para transformar su mundo o contexto, ya sea social, económico, espiritual, de talento, etc. La educación actual sólo apunta a la racionalidad del educando y obtiene pésimos resultados, que reflejan sus falencias a la hora de enseñar y evaluar (Naranjo, 2007). Se dice en la escuela que cuando los niños juegan no aprenden lo que debieran aprender. Pero cuando aprenden no juegan y de igual forma no aprenden lo que debieran aprender y se frustran. Enfocarse sólo en la dimensión lingüística y aritmética es una limitación excesiva, que responde exclusivamente al perfil de las competencias capitalistas (Luna, 2008), donde el juego no sirve para el trabajo, sólo para el ocio. Entonces, a medida que vamos creciendo o escolarizandonos, jugamos cada vez menos, marginado nuestro bucle educativo-lúdico del conocer.

\section{Conclusiones}

Los primeros niveles bio-epistémicos de limitación de la dimensión lúdica del niño, en el primer contacto con el contexto escolar, son múltiples, efectivos, normalizadores y repercuten a lo largo de toda la estadía en la escuela y en nuestras interacciones futuras en el mundo. El contexto escolar no se relaciona positivamente con el juego. La dimensión lúdica es controlada, pero su éxito encierra costos severos en el desarrollo de los educandos, cuya libertad y derecho a jugar tiende a suprimirse al máximo. Además, 
la dicotomía artificial y engañosa de aprendizaje versus juego, construye un falso conocimiento con respecto a dos fenómenos de la vida, que siempre han estado unidos y entramados de manera positiva, a lo largo de toda la existencia de la humanidad. A medida que avanzamos en nuestra edad cronológica, el juego nos parece antinómico del trabajo y la seriedad. Ya no podemos seguir descubriendo el mundo a través del juego. La sociedad comienza a poner frenos a nuestro derecho a jugar, a través de etiquetas serias como el estudio académico, el trabajo y la ciudadanía. Nos hacemos "grandes" y el juego ya no nos puede acompañar en nuestro viaje experiencial, y queda marginado a momentos de ocio y tiempo libre, es decir, cuando no estudiamos en la escuela, cuando ya hemos trabajado, cuando ya nos hemos preocupado de actividades "realmente importantes"

El proceso educativo se bifurca exclusivamente en la disciplina-orden (exigida por los docentes) y la indisciplina -desorden (propuesta por los educandos). Por lo mismo, las manifestaciones lúdicas, que la mayoría de las veces emergen desde los niños, son rápidamente suprimidas. Aquí la complejidad e importancia que le otorgamos, ya que al mismo efecto que acompaña el no alimentarnos y que como consecuencia nos hace enfermar a nivel biológico, el no jugar también nos hace seres enfermos a un nivel epistemológico. Y si los niños no tienen la posibilidad de aprender a través del juego o de otras formas posibles, entonces, estamos limitando su forma de conocer y afectando su desarrollo humano holístico. El primer paso a la "experiencia escolar" resulta extremadamente limitante para el niño y su relación con el mundo, a través del juego. Los procesos escolarizados necesitan más armonía educativa, un balance que otorgue más oportunidades de aprendizaje a los educandos. El juego reúne los conocimientos, nunca los separa. Tiene la capacidad de satisfacer las inquietudes del ser humano creativo y en constante búsqueda. A través del juego, el aprendizaje es grato, alegre, divertido, significativo y dinámico. Potenciando diferentes aspectos del niño y muchas otras categorías inéditas e inciertas que pudieran ser parte de su naturaleza.

\section{Referencias bibliográficas}

Butendieck, S. (2003). La Importancia de la Motricidad Libre y Autónoma en el Bebé. Edit. AntroIbero. Chile. 
Caillois, R. (1986). Los Juegos y los Hombres: La Máscara y el Vértigo. Fondo de Cultura Económica de España, S.L.

Calvo, C. (2007). Del Mapa Escolar al Territorio Educativo. Disoñando la Escuela desde la Educación. Edit. Nueva Mirada. Santiago de Chile.

Díaz Mejía, H. (2006). La Función Lúdica Del Sujeto: Una Interpretación Teórica Para Transformar Las Prácticas Pedagógicas. Edit. Corporativa Editorial Magisterio. Bogotá.

Fleer, M. (1996). Play through the profiles: profiles play. Australian Early Childhood association, Inc. Watson.

García, A. (1998). Los Juegos en la Educación Física de los 6 a los 12 Años. Edit. Inde. Barcelona.

Huizinga, J. (2000). Homo Ludens. Edit. Alianza. Madrid.

Illich, I. (1977). Educación sin Escuelas. Edit. Península. Barcelona, España.

Luna, J. (2008). Complejidad en Educación. Nau Llibres. Chile.

Maturana, H. (2003). Amor y Juego: Fundamentos Olvidados de lo Humano Desde el Patriarcado a la Democracia. Edit. J.C. Sáez editor. Chile.

Morin, E. (2007). Los Siete Saberes Necesarios para la Educación del Futuro. Edit. Nueva visión 2007. Buenos aires.

Naranjo, Claudio. (2007). Cambiar la Educación para Cambiar el Mundo. Edit. Cuarto Propio. Chile.

Paymal, N. (2010). La Pedagogía 3000. Edit. Librería Armonía y Ox La-Hun. La Paz, Bolivia.

Puig, M.C. (1994). El Juego, en Varios, Educación y su Didáctica. Edit. Alcalá de Henares.

Trigo, E. (1999). Creatividad y Motricidad. Edit. Inde. Barcelona.

UNESCO. (1980). El Niño y el Juego: Planteamientos Teóricos y Aplicaciones Pedagógicas. Edit. Unesco. Francia. 